\title{
KAJIAN PERAN WADUK SEBAGAI PENGENDALI KUALITAS AIR SECARA ALAMI
}

\author{
Agung B. Supangat ${ }^{1}$ dan Paimin ${ }^{2}$ \\ 1) Balai Penelitian Hutan Penghasil Serat (BPHPS) Kuok \\ Jl. Raya Bangkinang - Kuok Km. 9 Bangkinang 28401, \\ Kotak Pos 4/BKN - Riau. Telp : (0762) 71000121, Fax : (0762) 71000122, 21370 \\ 2) Balai Penelitian Kehutanan Solo (BPK Solo) \\ Jl. A. Yani Pabelan PO. BOX 295 Kartasura - Solo. \\ Telp: (0271) 716709, Fax: (0271) 716959 \\ E-mail: absupangat@yahoo.com,paimin@yahoo.com
}

\begin{abstract}
$\mathscr{\mathscr { O }}$

Indonesia it was identified that there were much of polluted stream flow which cause improper consumed water. One of the rivers which has low of water qualities is Citarum River, West Java. However, along the Citarum river, there were built three reservoir dams (Saguling, Cirata and Jatilubur) that can control the condition of river water regime. Research was conducted in Citarum watershed to determine the role of those reservoirs on water quality control. Seven stations along the river were selected as observation posts of water samples. Based on the observation results it was indicated that water pollutants within Citarum river was very high. However, those pollutants could be purified or reduced by those reservoirs, hence water discharge from the reservoirs has better quality. In the future, deposition of those pollutants within the dam may has negative environment impact. Therefore, to sustain that function of the dam, comprehensive efforts on reducing pollutants from the catchment area is urgently required.
\end{abstract}

Keywords: Citarum River, River Water Quality, Pollutant, Reservoir Roles

\section{PENDAHULUAN}

Air merupakan salah satu kebutuhan paling vital dalam berbagai proses metabolisme kehidupan dari makhluk hidup. Meskipun air termasuk sumberdaya alam yang dapat diperbaharui oleh alam, namun kenyataannya bahwa ketersediaan air tawar tidak pernah bertambah (Kantor Menteri Negara KLH, 1992). Banyak daerah di Indonesia masih kesulitan mendapatkan air bersih untuk kebutuhan hidup sehari-hari sehingga bendampak pada munculnya berbagai macam penyakit. Penggunaan air minum yang tidak memenuhi syarat kesehatan mengakibatkan penduduk terserang penyakit saluran pencernaan dan diare yang setiap tahunnya diperkirakan lebih dari 3,5 juta anak di bawah usia tiga tahun dengan jumlah kematian $3 \%$ atau 105.000 jiwa (Raini, dkk., 1995). Penggunaan air sungai sebagai salah satu penopang hidup masyarakat di Indonesia terkendala oleh tidak layaknya kondisi air yang ada. Banyak aliran sungai di Indonesia yang telah tercemar dan tidak layak lagi dikonsumsi untuk berbagai kebutuhan.

Salah satu sungai yang kondisinya cukup parah adalah sungai Citarum di Jawa Barat. Sungai Citarum memiliki panjang sungai 270 kilometer, yang berhulu di Gunung Wayang, Kabupaten Bandung, melintasi beberapa wilayah kabupaten 
seperti Kabupaten Cianjur dan Kabupaten Purwakarta dan berhilir di Jakarta, Bekasi dan Karawang. Lebih dari 9 juta penduduk hidup di kawasan DAS (daerah aliran sungai) Citarum dan sebagian besar memanfaatkan air sungai Citarum untuk kehidupannya. Air Sungai Citarum sebagian besar (>85\%) digunakan untuk irigasi, dan sisanya untuk kebutuhan domestik dan air industri (Miyazato dan Khan, 2004)

Permasalahan sumberdaya air Sungai Citarum terjadi mulai dari hulu, tengah sampai hilir antara lain tingginya tingkat sedimentasi sebagai akibat erosi tanah, rendahnya kualitas air sungai akibat tingginya kandungan polutan dalam air, kekeringan di musim kemarau dan banjir di musim penghujan, eksploitasi air tanah yang berlebihan sehingga mengakibatkan draw down yang berlebih, pembuangan limbah dari pabrik serta penggunaan lahan yang buruk (Miyazato dan Khan, 2004). Beberapa laporan menyebutkan bahwa polusi air di Waduk Saguling di aliran Sungai Citarum telah mencapai tingkat yang membahayakan terutama di musim kemarau (Yoga, dkk., 2006). Waduk Saguling telah terkontaminasi dengan kandungan polutan yang tinggi oleh limbah domestik dan industri yang berasal dari kawasan Kota Bandung (dengan populasi penduduk sekitar 2 juta jiwa). Polusi ini menyebabkan eutrofikasi dari tanaman enceng gondok serta berkembangnya racun cyanobacterial yang dapat mematikan biota air (Hart, et al., 2002).

Di sepanjang aliran Sungai Citarum terdapat 3 (tiga) waduk besar yang secara berurutan dari hulu yaitu Waduk Saguling, Cirata, dan Djuanda (Jatiluhur). Ketiganya dimanfaatkan sebagai pembangkit listrik tenaga air (PLTA) serta untuk memenuhi kebutuhan air irigasi sawah di sebagian besar wilayah dari Kabupaten Cianjur, Kabupaten Purwakarta sampai wilayah pesisir di Kabupaten Karawang, dan Kabupaten Bekasi, serta digunakan untuk pasokan air minum DKI Jakarta. Fungsi atau peran utama waduk sebenarnya untuk dapat mengendalikan sumberdaya air baik secara kualitas, kuantitas maupun kontinyuitas. Sebagai pengendali kualitas air, waduk memiliki kemampuan untuk melakukan penjernihan atau pembersihan air yang tertampung secara alami (natural selfpurification capacity) dari bahan tersuspensi maupun terlarut sehingga air yang dilepas dari waduk bisa memenuhi baku mutu air irigasi, pembudayaan ikan air tawar, dan peternakan.

Memperhatikan permasalahan di DAS Citarum tersebut, penelitian ini bertujuan untuk mengetahui tingkat peran waduk yang berada di sepanjang sungai Citarum dalam mengendalikan kualitas air sungai.

\section{METODE PENELITIAN}

\section{Bahan dan Peralatan}

Bahan kajian terdiri dari data dan informasi dari instansi terkait melalui survai data sekunder serta hasil pengamatan langsung kualitas air sungai. Peralatan kajian berupa peralatan alat tulis kantor, kalkulator dan komputer.

\section{Cara}

Penelitian dilaksanakan pada tahun 2006. Lokasi penelitian dilaksanakan di daerah aliran sungai (DAS) Citarum, Jawa Barat, seperi Gambar 1 (tanpa skala, PUSAIR, 1998). Luas DAS Citarum meliputi $6.080 \mathrm{~km}$, terletak pada garis $05^{\circ} 55^{\prime} 00^{\prime \prime}-07^{\circ} 10^{\prime} 00^{\prime \prime}$ LS dan $107^{\circ} 02^{\prime} 00^{\prime \prime}$ 
- $107^{0} 39^{\prime} 00^{\prime \prime B T}$. Panjang sungai $269 \mathrm{~km}$ yang mengalir dari hulu Gunung Tangkuban Perahu, Gunung Patuha, dan elevasi tertinggi di Gunung Pangrango $(3.019 \mathrm{~m}$ dpl) yang kemudian bermuara di Laut Jawa.

Sepanjang Sungai Citarum telah dibangun 3 (tiga) waduk besar secara seri dari hulu ke hilir dengan kapasitas tampung dan tahun pembuatan sebagai berikut: Waduk Saguling (982 juta $\left.\mathrm{m}^{3}, 1986\right)$, Waduk Cirata (2.165 juta $\left.\mathrm{m}^{3}, 1988\right)$, dan Waduk Jatiluhur (3.000 juta $\left.\mathrm{m}^{3}, 1963\right)$. Secara umum penggunaan lahan DAS Citarum terdiri dari hutan $(10,49 \%)$, sawah $(24,79 \%)$, tanah pertanian lainnya $(46,02 \%)$, lain-lain $(18,70 \%)$ (PUSAIR, 1998).

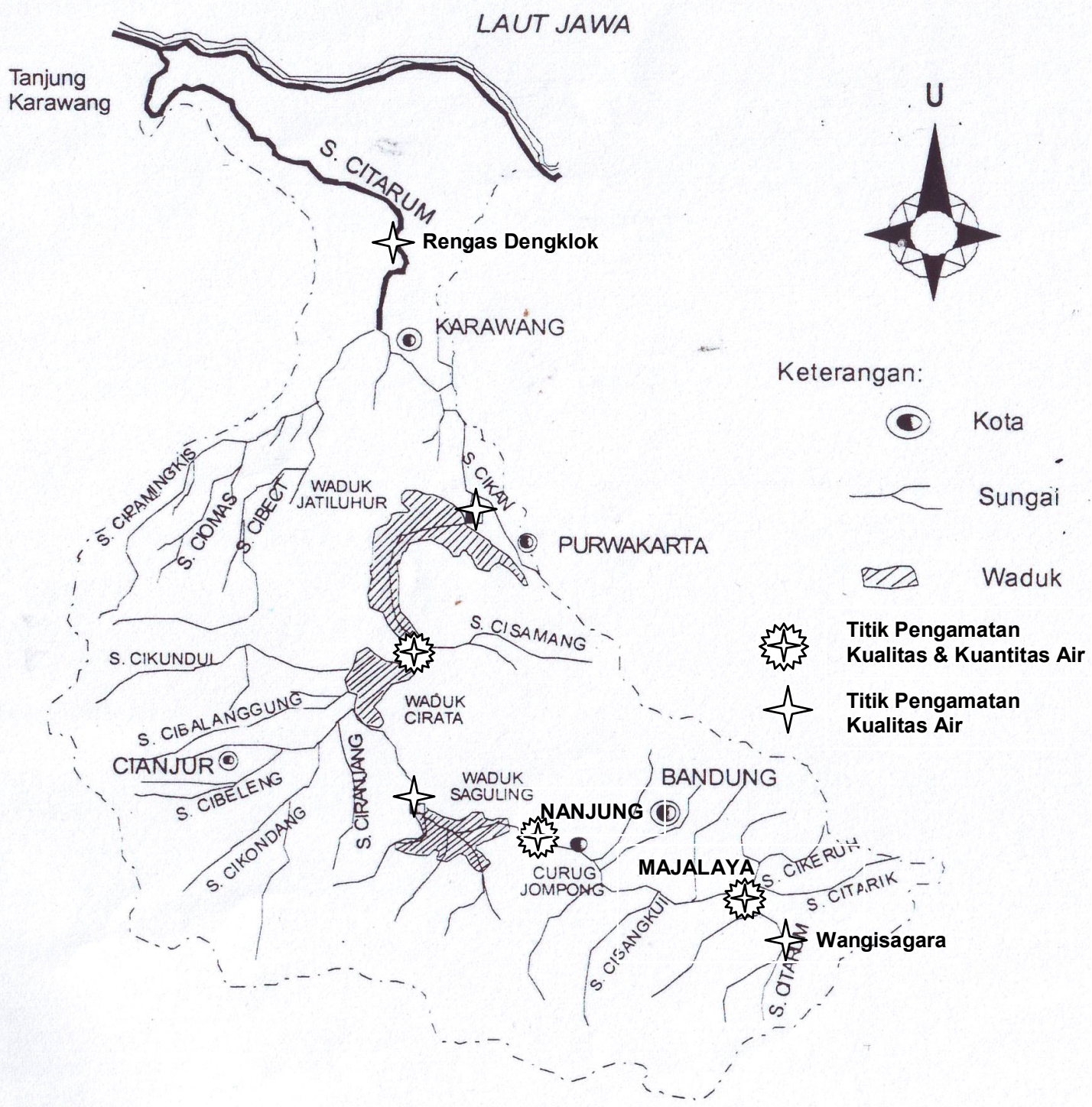

Gambar 1. Peta DAS Citarum dan Titik Pengamatan Aliran Air (Sumber: PUSAIR, 1998)

(Figure 1. Map of Citarum Watershed and Water Observation Locations.

Source: PUSAIR, 1998) 
Penelitian ini merupakan penelitian survei dengan menghimpun data dan informasi primer maupun sekunder. Data dan informasi sekunder yang berupa data meteorologi dan kuantitas aliran air (debit sungai) diperoleh dari berbagai instansi terkait. Sedangkan data kualitas air diambil secara langsung di lapangan pada titik pengamatan yang telah ditentukan serta dari instansi terkait (sekunder). Pengambilan data mencakup seluruh aliran Sungai Citarum, dari hulu sampai hilir.

Pembagian wilayah hulu, tengah dan hilir dari Sungai Citarum dalam penelitian ini dikategorikan sebagai berikut (Paimin, dkk., 2006):

- Wilayah Hulu: mulai dari sumber mata air Sungai Citarum sampai outlet Waduk Saguling

- Wilayah Tengah: mulai dari outlet Waduk Saguling sampai inlet Waduk Jatiluhur

- Wilayah Hilir: mulai dari inlet Waduk Jatiluhur sampai Outlet DAS Citarum di Pantai Karawang-Bekasi

Titik pengamatan/pemantauan aliran sungai (stream flow) dari hulu sampai hilir secara skematis seperti pada Gambar 1. Pengamatan kualitas air dilakukan dengan mengambil sampel air pada musim hujan (Januari 2006) dan pada musim kemarau (Agustus 2006). Titik pengambilan sampel dari hulu secara berurutan sampai sampai hilir adalah (lihat Gambar 1): Wangisagara, Majalaya, Nanjung, Outlet Saguling, Outlet Cirata, Outlet Jatiluhur, Rengas Dengklok. Sedangkan titik pemantauan kuantitas (debit) aliran dilakukan di pos duga air (stream ganging station) mulai dari hulu di Majalaya, Nanjung, sampai di inlet Waduk Juanda (Jatiluhur), dengan luas daerah tangkapan air berturut-turut $177,0 \mathrm{~km}^{2}$, $1.674,5 \mathrm{~km}^{2}$, dan $5.642,0 \mathrm{~km}^{2}$.
Anasir data dan parameter yang dibutuhkan antara lain:

- Data klimatologi di DAS Citarum

- Data curah hujan bulanan selama 10 tahun terakhir di berbagai lokasi (hulu, tengah dan hilir DAS)

- Data pengukuran debit air sungai selama 10 tahun terakhir di tiga pos duga air Majalaya, Nanjung, dan di inlet Waduk Juanda

- Data kualitas air dan pengamatan langsung kualitas air sungai Citarum pada musim hujan dan kemarau di tujuh titik pengamatan.

Data sekunder diperoleh dari instasi: Perum Jasa Titra (PJT) II Waduk Jatiluhur, Balai Pengelolaan Sumberdaya Air (BPSDA) Wilayah Sungai Citarum, Pusat Penelitian dan Pengembangan Sumberdaya Air (PUSAIR), dan instansi daerah terkait lainnya. Sampel air dianalisis di laboratorium untuk memperoleh unsur kualitas air yang meliputi Total Dissolved Solutes (TDS), kekeruhan, pH, Dissolved Oxygen (DO), nitrit, amoniak B, Biochemical Oxygen Demand (BOD), dan Chemical Oxygen Demand (COD)

Pengolahan data curah hujan, debit aliran, dan kalitas air, dilakukan dengan tabulasi data dan perhitungan sebaran data bulanan, dan disajikan dalam bentuk tabel dan grafik kecenderungan, baik berdasarkan fungsi waktu (bulan) maupun ruang (dari hulu hingga hilir DAS). Analisis data dilakukan dengan menggunakan analisis kecenderungan (trend analysis) untuk mengetahui kecenderungan perubahan parameter tata air sebagai cerminan pengaruh keberadaan (peran) waduk sebagai pengendali kualitas, kuantitas, dan distribusi aliran air Sungai Citarum. 
HASIL DAN PEMBAHASAN

\section{Kondisi Iklim dan Curah Hujan}

Wilayah hulu DAS Citarum memiliki rata-rata suhu harian $24,2{ }^{\circ} \mathrm{C}$, kelembaban relatif rata-rata $94,9 \%$, kecepatan angin rata-rata $83,2 \mathrm{Km} /$ hari, penyinaran matahari rata-rata 53,5\%, serta penguapan rata-rata 4,6 mm/hari (PUSAIR, 1998). Di wilayah tengah, suhu rata-rata harian sebesar 26,05 ${ }^{\circ} \mathrm{C}$ dimana suhu maksimum terjadi pada bulan April $\left(30,4^{\circ} \mathrm{C}\right)$ dan suhu minimum terjadi pada bulan Agustus $\left(21,7^{\circ} \mathrm{C}\right)$.

Berdasarkan informasi dari instansi terkait (BPSDA Wilayah Sungai Citarum, BPDAS Citarum Cimanuk, serta Perum Jasa Tirta II Jatiluhur), diketahui bahwa selama periode 1994-2005, curah hujan $(\mathrm{CH})$ tahunan rata-rata di wilayah hulu sebesar $2.362 \mathrm{~mm}$ (rata-rata dari 5 pos penakar hujan), di wilayah tengah sebesar $2.086 \mathrm{~mm}$
Berdasarkan data dan Gambar 2, terlihat bahwa di bagian hulu dan tengah dari DAS Citarum memiliki curah hujan yang tergolong tinggi (di atas $2.000 \mathrm{~mm}$ / th), yang meliputi daerah administratif Kabupaten Bandung, Kabupaten Cianjur sampai wilayah Kabupaten Purwakarta bagian selatan. Sedangkan di bagian hilir merupakan daerah yang lebih kering dengan curah hujan di bawah $2.000 \mathrm{~mm} /$ th, meliputi daerah Purwakarta bagian utara sampai Kabupaten Karawang dan Kabupaten Bekasi. Berdasarkan sebaran curah hujan bulanan rata-rata (Gambar 2), terlihat bahwa bulan-bulan basah $(\mathrm{CH}>$ $100 \mathrm{~mm} /$ bulan) terjadi pada bulan Oktober sampai Maret; sedangkan bulan yang lain (April sampai September) termasuk bulan kering $(\mathrm{CH}<100 \mathrm{~mm} /$ bulan).

Jika dilihat pada curah hujan tahunan (Gambar 3), hampir ada kemiripan fluktunsi sebaran curah hujan pada ketiga S (hulu, tengah dan hilir), hanya yang berbeda. Pada tahun, 2000, dan 2003, hampir di ayah DAS Citarum mengalami

Gambar 2. Sebaran Curah Hujan Bulanan Rata-Rata Di DAS Citarum (Figure 2. Distribution of The Average of Monthly Rainfall in Citarum Watershed) 


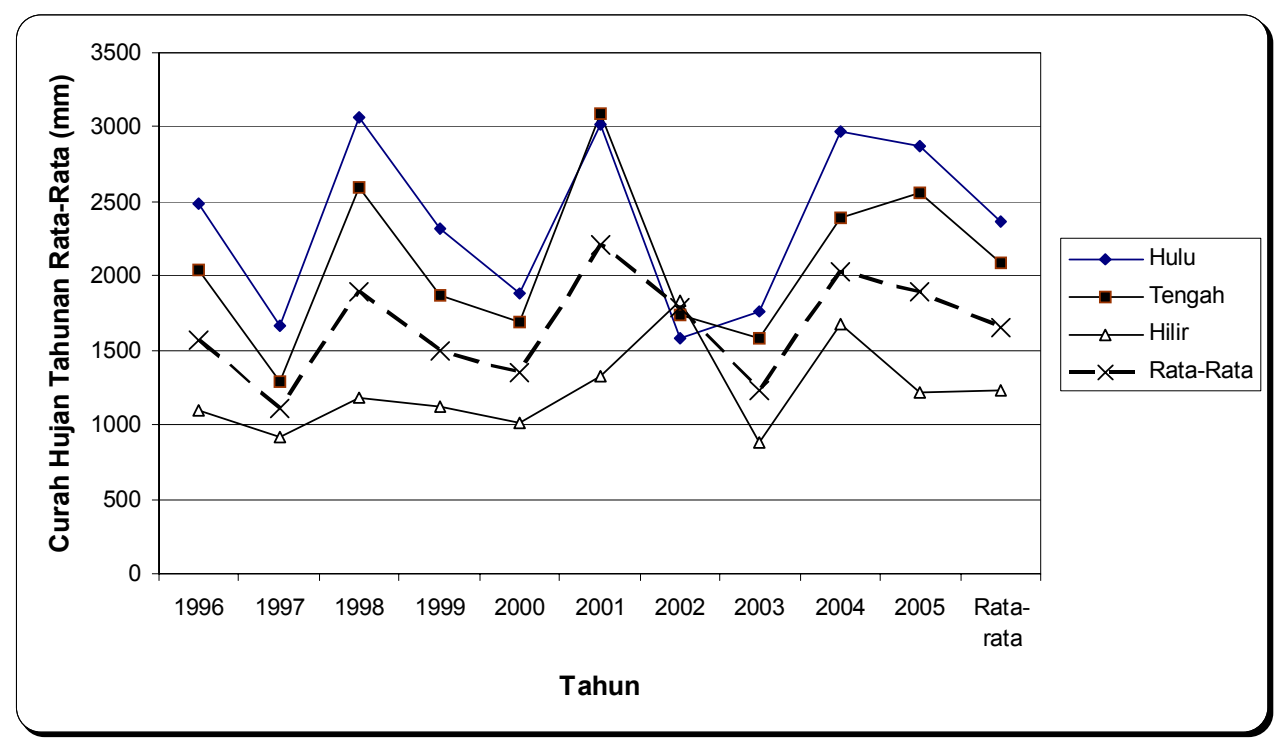

Gambar 3. Sebaran Curah Hujan Tahunan Di DAS Citarum, 1996 - 2005 (Figure 3. Distribution of Annual Rainfall in Citarum Watershed, 1996 - 2005)

kekeringan ( $\mathrm{CH}<1.500 \mathrm{~mm} /$ tahun). Sebaliknya, pada tahun-tahun 1998, 2001, dan 2004-2005, curah hujan di atas 2.000 $\mathrm{mm} /$ tahun Fluktuasi ini memperlihatkan bahwa fluktuasi curah hujan pada DAS Citarum hampir seragam, tetapi besarnya curah hujan rata-rata tahunan cukup berbeda antara wilayah hulu, tengah dan hilir DAS.

Potensi curah hujan yang cukup tinggi terutama dari hulu DAS akan berdampak pada tingginya potensi debit air sungai yang dihasilkan. Kondisi debit air yang cukup tinggi akan berpotensi membawa/mengangkut polutan air dari limbah praktek pertanian dan limbah industri maupun domestik ke dalam badan air sungai yang kemudian terakumulasi dan terendapakan dalam waduk.

\section{Kuantitas dan Kualitas Aliran Air Sungai}

Berdasarkan data hasil pemantauan aliran Sungai Citarum pada tiga pos duga air yang dilakukan oleh Pusat Litbang Pengairan, Balai Pengelolaan Sumber Daya Air (BPSDA) Sungai Citarum, dan Perum Jasa Tirta (PJT) II, diperoleh data debit ratarata harian pada tiap-tiap bulan selama 10 tahun (1993 - 2002) seperti pada Tabel 1. Rata-rata debit harian pada sungai Citarum di wilayah pemantauan paling hulu (Citarum-Majalaya) adalah sebesar 181,36 $\mathrm{m}^{3} /$ detik, di wilayah tengah (CitarumNanjung) sebesar $73,16 \mathrm{~m}^{3} /$ detik, sedangkan di wilayah hilir (di inlet Waduk Jatiluhur) sebesar 183,54 $\mathrm{m}^{3} /$ detik.

Kondisi fluktuasi sebaran debit ratarata harian di Sungai Citarum disajikan pada Gambar 4. Berdasarkan Tabel 1 dan Gambar 4, dapat dijelaskan bahwa debit harian rata-rata di sepanjang Sungai Citarum sangat fluktuatif. Dari ketiga titik pos duga air yang diamati, terlihat fenomena menarik. Pada pos duga Majalaya yang berada di hulu (sebelum memasuki Kota Bandung), kondisi debit air masih cukup tinggi, tetapi pada pos duga Nanjung yang 
Tabel 1. Debit Air Rata-Rata Harian Setiap Bulan di Sungai Citarum (Table 1. The Average of Daily Water Discharge for Each Month of Citarum River)

\begin{tabular}{|c|c|c|c|c|c|c|c|c|c|c|c|c|}
\hline \multirow{2}{*}{$\begin{array}{l}\text { Stasiun } \\
\text { (Station) }\end{array}$} & \multicolumn{7}{|c|}{ Debit Rata-Rata Harian (Daily Average Discharge) (m $3 / \mathrm{dt})$} \\
\cline { 2 - 13 } & Jan & Feb & Mar & Apr & May & Jun & Jul & Aug & Sep & Oct & Nov & Dec \\
\hline $\begin{array}{l}\text { Citarum - } \\
\text { Majalaya }\end{array}$ & 261,0 & 280,3 & 339,9 & 242,7 & 142,0 & 144,6 & 113,0 & 40,6 & 35,0 & 134,6 & 195,1 & 247,5 \\
\hline $\begin{array}{l}\text { Citarum - } \\
\text { Nanjung }\end{array}$ & 80,6 & 112,9 & 119,9 & 131,8 & 86,0 & 48,5 & 69,6 & 24,0 & 21,7 & 43,0 & 72,1 & 68,2 \\
\hline $\begin{array}{l}\text { Citarum - } \\
\text { Jatiluhur }\end{array}$ & 248,4 & 279,2 & 289,5 & 310,5 & 223,3 & 154,9 & 105,2 & 58,1 & 56,2 & 119,2 & 195,2 & 162,6 \\
\hline Rata-rata & 196,7 & 224,1 & 249,8 & 228,3 & 150,4 & 116,0 & 95,9 & 40,9 & 37,6 & 98,9 & 154,1 & 159,4 \\
\hline
\end{tabular}

Sumber (Source): Puslitbang Pengairan (1993-2002), BPSDA S. Citarum (1993-2002), PJT II (1994-2002)

berada di inlet Waduk Saguling kondisi debit air telah menyusut cukup tajam.

Pada pos duga inlet Waduk Jatiluhur, terlihat kondisi debit mengalami kenaikan. Besarnya debit aliran pada pos ini tergantung dari sistem pengoperasian air di Waduk Saguling dan Waduk Cirata yang berada di hulunya serta kemungkinan penambahan debit dari anak-anak Sungai Citarum yang bermuara di Waduk Cirata seperti Sungai Cisokan dan Sungai Cibalagung yang berhulu di Cianjur. Berdasarkan sebaran data bulanan dari debit harian rata-rata (Gambar 4), terlihat adanya kecenderungan fluktuasi tiap bulan yang hampir seragam antara wilayah hulu, tengah,dan hilir. Debit rata-rata tertinggi terjadi pada bulan Februari-Maret, sedangkan debit terendah terjadi pada bulan Agustus-September.

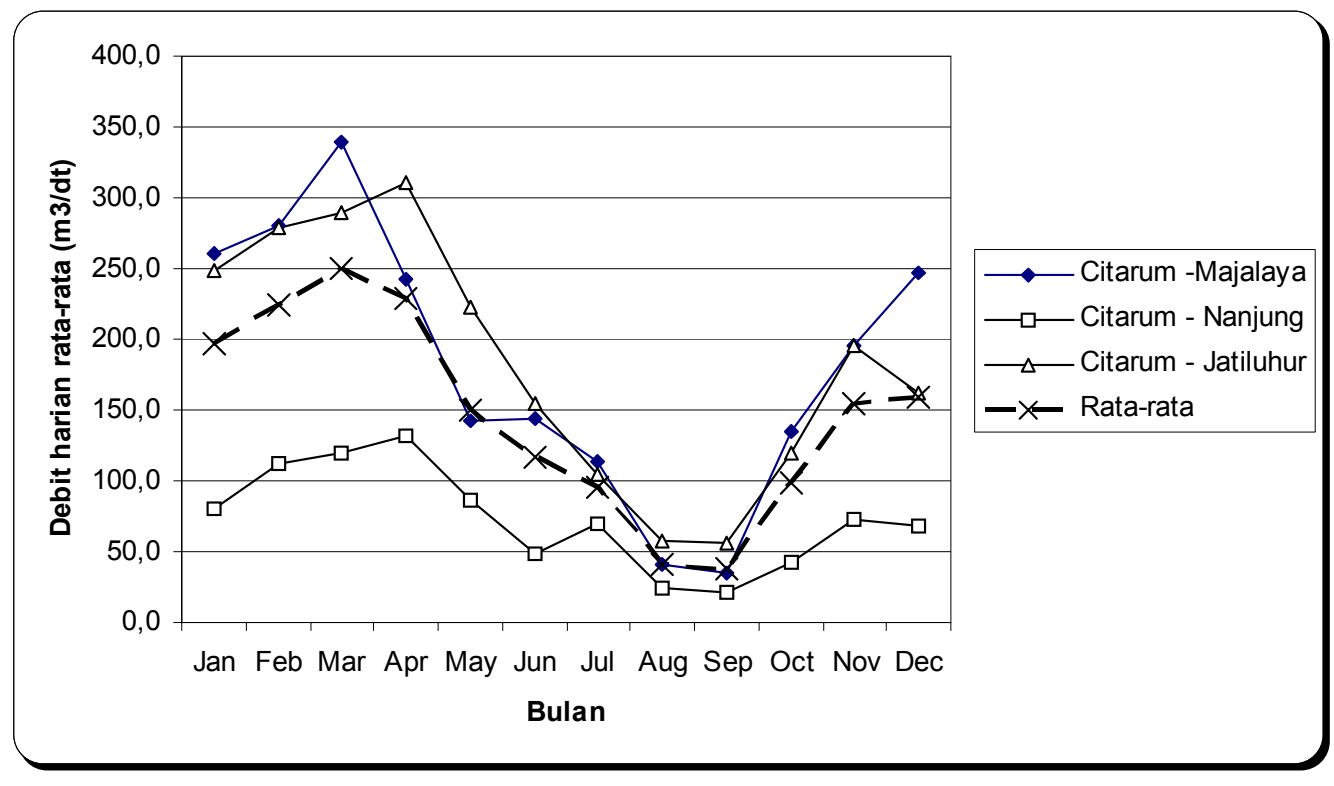

Gambar 4. Sebaran Debit Air Rata-Rata Harian di Sungai Citarum (Figure 4. Distribution of The Average of Daily Water Discharge in Citarum River) 
Kondisi debit air sungai dari hulu (pos duga Majalaya) yang tinggi berpotensi mempercepat proses kontaminasi badan air oleh polutan yang berasal dari berbagai sumber baik dari limbah pertanian di hulu DAS, limbah domestik maupun dari buangan limbah industri yang banyak berada di kawasan Bandung bagian selatan. Menurunnya debit pada pos duga Nanjung yang merupakan pintu masuk pada Waduk Saguling, telah menyebabkan meningkatnya konsentrasi kandungan bahan pencemar dalam air. Oleh karenanya, kondisi kualitas air di pos duga Nanjung (inlet Waduk Saguling) sangat buruk dan berdampak pada kondisi air di badan Waduk Saguling menjadi yang terparah kualitas airnya (Hart, et al., 2002; Yoga, dkk., 2006).

Tabel 2. Hasil Analisis Kualitas Air pada Musim Hujan dan Kemarau di Sungai Citarum (Table 2. Analysis Results of Water Quality At Rainy and Dry Seasons of Citarum River)

\begin{tabular}{|c|c|c|c|c|c|c|c|c|c|}
\hline \multirow{2}{*}{$\begin{array}{l}\text { Parameter } \\
\text { (Parameters) }\end{array}$} & \multirow{2}{*}{$\begin{array}{l}\text { Musim } \\
\text { (Season) }\end{array}$} & \multicolumn{7}{|c|}{ Pos Pengambilan Sampel Air (Observation Stations) } & \multirow{2}{*}{$\begin{array}{l}\text { Baku Mutu } \\
\text { (Standard } \\
\text { of quality)*) }\end{array}$} \\
\hline & & $\begin{array}{l}\text { Wangi- } \\
\text { sagara }\end{array}$ & Majalaya & Nanjung & $\begin{array}{c}\text { Outlet } \\
\text { Saguling }\end{array}$ & $\begin{array}{l}\text { Outlet } \\
\text { Cirata }\end{array}$ & $\begin{array}{c}\text { Outlet } \\
\text { Jatiluhur }\end{array}$ & $\begin{array}{l}\text { Rengas } \\
\text { Dengklok }\end{array}$ & \\
\hline \multirow{3}{*}{$\begin{array}{l}\text { TDS } \\
(\mathrm{mg} / \mathrm{l})\end{array}$} & Basah (Wet) & 116 & 345 & 289 & 135 & 84 & 49 & 127 & \multirow{3}{*}{1000} \\
\hline & Kering $(D y)$ & 100 & 112 & 290 & 125 & 300 & 90 & 352 & \\
\hline & Rata-2 (Average) & 108,0 & 228,5 & 289,5 & 130,0 & 192,0 & 69,5 & 239,5 & \\
\hline \multirow{3}{*}{$\begin{array}{l}\text { Kekeruhan } \\
\text { (NTU) }\end{array}$} & Basah (Wet) & 273 & 6474 & 5385 & 1264 & 319 & 93 & 4862 & \multirow{3}{*}{-} \\
\hline & Kering (Dry) & 170 & 579 & 1005 & 40,7 & 50,8 & 85 & 595 & \\
\hline & Rata-2 (Average) & 221,5 & 3526,5 & 3195,0 & 652,4 & 184,9 & 89,0 & 2728,5 & \\
\hline \multirow{3}{*}{$\mathrm{pH}$} & Basah (Wet) & 6,1 & 6,5 & 7,1 & 7,1 & 6,8 & 6,8 & 7 & \multirow{3}{*}{$6-9$} \\
\hline & Kering (Dry) & 6,8 & 6,5 & 7,9 & 6,9 & 6,8 & 7,08 & 6,9 & \\
\hline & Rata-2 (Average) & 6,5 & 6,5 & 7,5 & 7,0 & 6,8 & 6,9 & 7,0 & \\
\hline \multirow{3}{*}{$\begin{array}{l}\text { DO } \\
(\mathrm{mg} / \mathrm{l})\end{array}$} & Basah (Wet) & 6,1 & 5,8 & 4,1 & 3,9 & 4,8 & 5 & 4,8 & \multirow{3}{*}{$>3$} \\
\hline & Kering (Dry) & 6,6 & 6,1 & 6,3 & 6,6 & 6,5 & 6,8 & 6,2 & \\
\hline & Rata-2 (Average) & 6,4 & 6,0 & 5,2 & 5,3 & 5,7 & 5,9 & 5,5 & \\
\hline \multirow{3}{*}{$\begin{array}{l}\text { Nitrit } \\
(\mathrm{mg} / \mathrm{l})\end{array}$} & Basah (Wet) & 0,004 & 0,016 & 0,086 & 0,21 & 0,087 & 1,8 & 0,27 & \multirow{3}{*}{0,06} \\
\hline & Kering (Dry) & 0,06 & 0,05 & 0,06 & 0,06 & 0,06 & 0,08 & 0,136 & \\
\hline & Rata-2 (Average) & 0,03 & 0,03 & 0,07 & 0,14 & 0,07 & 0,94 & 0,20 & \\
\hline \multirow{3}{*}{$\begin{array}{l}\text { Amoniak B } \\
(\mathrm{mg} / \mathrm{l})\end{array}$} & Basah (Wet) & 0,012 & 0,022 & 0,17 & 0,82 & 0,14 & 0,27 & 0,019 & \multirow{3}{*}{0,5} \\
\hline & Kering $(D y y)$ & 0,08 & 0,052 & 2,95 & 1,05 & 0,29 & 1,12 & 0,48 & \\
\hline & Rata-2 (Average) & 0,05 & 0,04 & 1,56 & 0,94 & 0,22 & 0,70 & 0,25 & \\
\hline \multirow{3}{*}{$\begin{array}{l}\text { BOD } \\
(\mathrm{mg} / \mathrm{l})\end{array}$} & Basah (Wet) & 4,29 & 19,56 & 25,78 & 22,67 & 7,39 & 6,36 & 13,45 & \multirow{3}{*}{2} \\
\hline & Kering $(D r y)$ & 2,54 & 5,09 & 9,63 & 2,65 & 2,13 & 2,21 & 3,97 & \\
\hline & Rata-2 (Average) & 3,4 & 12,3 & 17,7 & 12,7 & 4,8 & 4,3 & 8,7 & \\
\hline \multirow{3}{*}{$\begin{array}{l}\text { COD } \\
(\mathrm{mg} / \mathrm{l})\end{array}$} & Basah (Wet) & 8,74 & 40,84 & 62,95 & 50,59 & 19,74 & 19,45 & 36,78 & \multirow{3}{*}{10} \\
\hline & Kering $(D r y)$ & 5,79 & 11,31 & 20,07 & 7,17 & 5,09 & 5,1 & 12,09 & \\
\hline & Rata-2 (Average) & 7,3 & 26,1 & 41,5 & 28,9 & 12,4 & 12,3 & 24,4 & \\
\hline
\end{tabular}

Keterangan (Remarks): - Musim Basah (Wet Season) : Januari (January)

$$
\text { - Musim Kering (Dry Season): Agustus (August) }
$$

Sumber (Source): Data Primer (Primary data) (2006) dan PJT II (2005).

*) PP. No. 82 Tahun 2001, Kelas I (Government Act No 82 Year of 2001 for First Class). 
Permasalahan kualitas air menjadi perhatian utama pada pengelolaan sumberdaya air sungai Citarum. Berbagai media dan publikasi hasil penelitian menyebutkan kondisi kualitas air sungai Citarum yang sangat buruk. Dalam penelitian ini pemantauan kualitas air dilakukan pada tujuh pos pemantauan, dimulai dari hulu, di pos Wangisagara yang berada di bawah mata air Sungai Citarum di Gunung Wayang dan dianggap belum mengalami banyak pencemaran, sampai di Sungai Citarum bagian hilir di Kecamatan Rengas Dengklok, Kabupaten Karawang. Hasil identifikasi kualitas air Sungai Citarum menggunakan hasil analisis data sekunder dari instansi terkait dan data primer yang diamati pada musim hujan dan kemarau secara lengkap disajikan pada Tabel 2 dan Gambar 5.

Berdasarkan Gambar 5 dan Tabel 2, kualitas air Sungai Citarum dari hulu sampai ke waduk Saguling (dari Wangisagara sampai Nanjung) cenderung semakin bu- ruk, kemudian terus mengalami perbaikan kualitas setelah melalui reservoir waduk (kecuali pada parameter Nitrit dan Amoniak Bebas), dan kemudian meningkat lagi pada daerah hilir (Rengas Dengklok). Kualitas air yang cenderung semakin buruk terutama akibat pencemaran oleh industri dan limbah domestik. Dibandingkan kondisi pada pos Wangisagara (yang belum tercemar), kondisi air di pos Majalaya sampai Rengas Dengklok banyak parameter yang melebihi ambang batas yang diperkenankan (baku mutu Kelas I, Kelas II, dan Kelas III, berdasarkan PP. No. 82 tahun 2001 tentang Pengelolaan Kualitas Air dan Pengendalian Pencemaran Air).

Beberapa parameter yang sangat buruk antara lain COD, BOD, kandungan Amoniak Bebas, Nitrit dan kekeruhan. Kondisi tersebut terjadi sejak pos pengamatan Majalaya yang meskipun berada di wilayah hulu tetapi banyak dipengaruhi industri tekstil yang ada di daerah Bandung

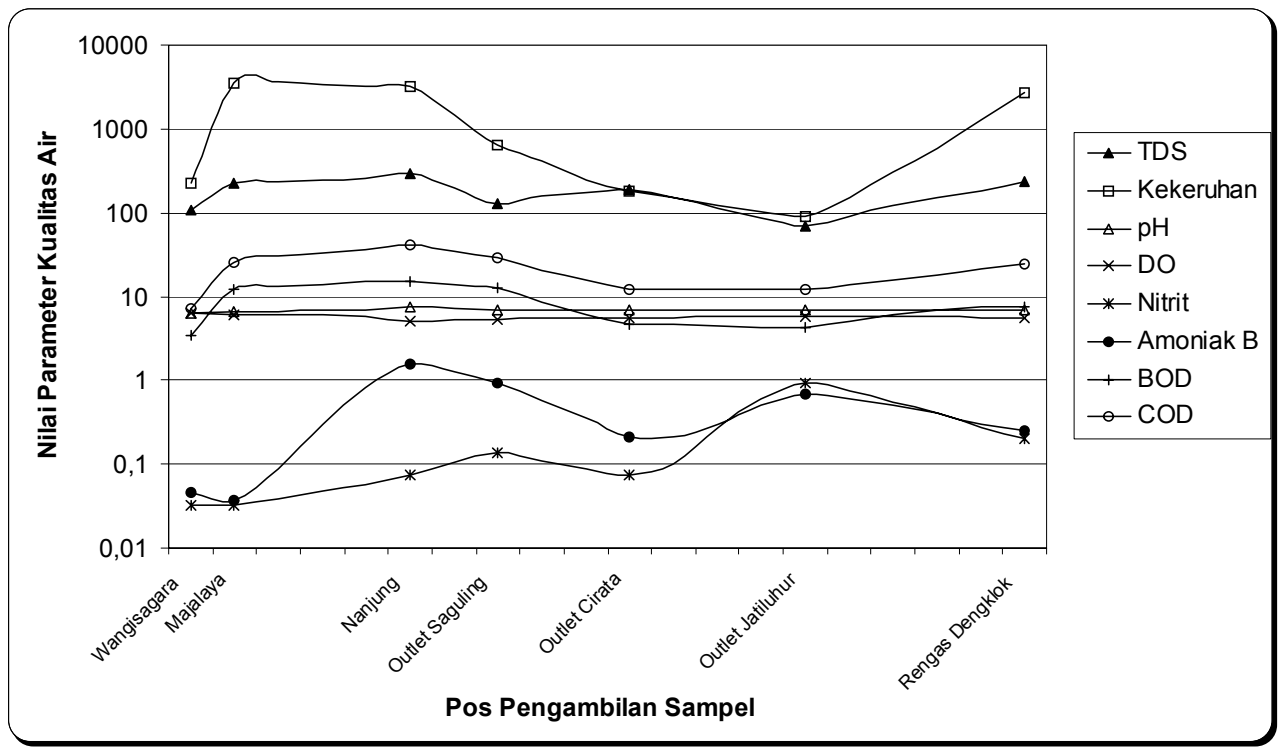

Gambar 5. Sebaran Kualitas Air Sungai Citarum Dari Hulu Ke Hilir Figure 5. Water Quality Distribution of Citarum River from the Upstream to Downstream) 
bagian selatan. Walaupun curah hujan cukup tinggi tetapi debit aliran dari Majalaya ke Nanjung mengalami penurunan sehingga kadar pencemar yang masuk sungai menjadi semakin tinggi. Demikian juga kualitas air yang keluar dari waduk Jatiluhur telah mengalami penurunan kadar bahan pencemarnya tetapi sampai ke Rengas Dengklok (hilir) semakin meningkat. Hal ini sebagai akibat dari bahan pencemar (polutan) dari berbagai industri dan sumber lain di sepanjang Sungai Citarum hilir yakni mulai dari Purwakarta sampai ke Karawang; disamping rendahnya pasokan air hujan sebagai pengangkut. Berdasarkan baku mutu tersebut, secara umum air Sungai Citarum (kecuali pos Wangisagara) belum memenuhi baku mutu air untuk Kelas I, Kelas II, dan Kelas III.

Hasil pengamatan tersebut menunjukkan bahwa waduk memiliki kemampuan untuk memulihkan atau purifikasi kondisi kualitas lingkungan air (kualitas air) secara alami, atau yang dikenal sebagai "natural selfpurification capacity”. Hasil tersebut sejalan dengan hasil penelitian Kumurur (2002) yang menyebutkan bahwa keberadaan Danau Tondanau dapat mengurangi pengaruh masukan bahan pencemar dari inlet danau baik dari limbah pertanian, rumah tangga dan erosi, sehingga air danau masih layak dikonsumsi ole masyarakat di bawahnya di Kota Manado. Demikian pula hasil pemantauan Bartram dan Balance (1996), menyimpulkan bahwa keberadaan reservoir dapat menurunkan kadar TDS dari kisaran nilai $100-1000 \mathrm{mg} / 1$ menjadi $40-1000 \mathrm{mg} /$ 1. Hasil penelitian lain di aliran Sungai Colorado juga menyimpulkan bahwa dampak pembangunan dan pengoperasian San Juan Cama telah menurunkan konduktan spesifik, konsentrasi sedimen terlarut dan menaikkan pH di Sungai Rio Chama dan
Sungai Rio Grande (Langman dan Anderholm, 2004).

Dibalik keberhasilan peran waduk sebagai purifikator bahan pencemar maka sebenarnya daerah genangan waduk sendiri merupakan daerah akumulasi pengendapan bahan polutan, baik bahan terlarut maupun tersuspensi, yang dikemudian hari kemungkinan memberikan dampak negatif terhadap lingkungan sekitarnya.

Agar peran dan fungsi waduk di sepanjang Sungai Citarum (Saguling, Citara, dan Jatilihur) sebagai pengendali kualitas air tidak mengalami penumpukan polutan yang tinggi maka pengendalian masukan bahan polutan dari daerah tangkapan airnya harus harus lebih ditingkatkan. Dari lahan budidaya, pengendalian erosi tanah harus ditingkatkan agar kekeruhan air dapat diturunkan, dan teknik budidaya tanaman ramah lingkungan perlu digalakkan untuk menurunkan bahan kimia polutan. Penyuluhan kepada masyarakat dan pengelola industri agar tidak membuang limbah (cair dan padat) ke badan air sungai atau waduk perlu terus diintensifkan. Terjadinya alih fungsi lahan yang tidak sesuai seperti dari hutan menjadi kawasan industri dapat menyebabkan fungsi vegetasi sebagai penyerap air dan penjerap polutan menjadi hilang. Hasil penelitian Kumurur (1998) menyebutkan bahwa akibat perubahan fungsi ruang di kawasan sekitar Danau Mooat dari tegalan ladang (kawasan budidaya) di sisi barat Danau Mooat menjadi tegalan sayur/kebun sayur (kawasan budidaya), berubahnya hutan belukar dan hutan lindung (kawasan lindung) di sisi timur danau menjadi areal perkebunan dan tegalan ladang (kawasan budidaya) sangat mempengaruhi peningkatan kadar fosfat. 


\section{KESIMPULAN DAN SARAN}

Berdasarkan hasil penelitian di daerah aliran sungai Citarum dapat disimpulkan:

1. Pasokan bahan polutan ke sungai Citarum dari hulu sampai hilir cukup tinggi sehingga melampaui ambang baku mutu Kelas I, Kelas II, dan Kelas III dalam PP No. 82 Tahun 2001.

2. Waduk Saguling, Cirata, dan Jatiluhur yang dibangun di sepanjang aliran Sungai Citarum dengan fungsi mengendalikan air sungai secara kuantitas dan kontinyuitas, terutama sebagai penyedia air irigasi, pengendali banjir, dan pembangkit listrik tenaga air, mampu juga berfungsi mengendalikan kualitas air sungai Citarum sehingga kandungan bahan polutan yang keluar dari waduk mengalami penurunan.

3. Adanya deposisi bahan polutan di dalam waduk perlu diwaspadai kemung- kinan dampak lingkungan di masa mendatang.

Untuk mempertahankan dan meningkatkan fungsi waduk secara berkelanjutan disarankan upaya pengendalian limbah secara komprehensif dari seluruh sumber bahan pencemar di daerah tangkapan air Sungai Citarum.

\section{UCAPAN TERIMA KASIH}

Ucapan terima kami sampaikan kepada Kepala Balai Penelitian Kehutanan Solo atas dukungan penyelenggaraan penelitian ini. Demikian juga kami kami mengucapkan rasa terima kasih yang sebesar-besarnya kepada Kepala Pusat Penelitian dan Pengembangan Sumberdaya Air, Direktur Perum Jasa Tirta II, dan Kepala Balai Pengelolaan Sumberdaya Air Sungai Citarum atas bantuan dan dukungan datanya.

\section{DAFTAR PUSTAKA}

Bartram, J. and R. Balance. 1996. Water Quality Monitoring - A Practical Guide to the Design and Implementation of Freshwater Quality Studies and Monitoring Programmes, Chapter 2 WATERQUALITY. Published on behalf of United Nations Environment Programme and the World Health Organization.

Dibyosaputro, S. 2005. "Muatan Suspensi Total dan Laju Sedimentasi Sungai Kayan di Kabupaten Bulungan, Kalimantan Timur”. Forum Geografi, Vol. 19, No. 2, Desember 2005. Hlm 115-126.

Hart, BT., WV. Dok and N. Djuangsih. 2002. Nutrient budget for Saguling Reservoir, West Java, Indonesia. Water Research 36 (2002) 2152-2160. www.elsevier.com/locate/watres

Kantor Meteri Negara KLH. 1992. Kualitas Lingkungan Hidup Indonesia 1992, 20 Tahun Setelah Stockholm. Jakarta.

Kumurur, V.A. 1998. Pengaruh Perubahan Pola Pemanfaatan Ruang Daratan Terhadap Eutrofikasi Danau (Studi Kasus: Pemanfaatan Ruang di Kawasan Sekitar Danau Mooat kabupaten Bolaang Mongondow, Propinsi Sulawesi Utara). Program Studi Ilmu Lingkungan Program Pascasarjana Universitas Indonesia, Jakarta 
Kumurur, V.A. 2002. Aspek Strategis Pengelolaan Danau Tondano Secara Terpadu. EKOTON Vol. 2, No. 1: 73-80, April 2002.

Langman, B. and S.K. Anderholm. 2004. Effects of Reservoir Installation, San Juan-Chama Project Water, and Reservoir Operations on Streamflow and Water Quality in the Rio Chama and Rio Grande, Northern and Central New Mexico, 1938-2000. Scientific Investigations Report 20045188. U.S. Geological Survey, Reston, Virginia. P:19-34.

Miyazato and M.E. Khan. 2004. Technical Assistance to The Republic Of Indonesia For Preparing The Integrated Citarum Water Resources Management Project. Asian Development Bank. Southeast Asia Department. TAR:INO 37049.

Paimin, Sukresno, Purwanto, A.B. Supangat, A. Wuryanta, N. Wahyuningrum. 2006. Laporan Kegiatan Penelitian Sistem Karakterisasi Daerah Aliran Sungai. Balai Litbang Teknologi Pengelolaan DAS-Indonesia Bagian Barat. Surakarta. (Tidak dipublikasikan)

Purnama, S. 2004. "Kualitas dan Tipe Kimia Airtanah di Dataran Pantai Kota Semarang". Forum Geografi, Vol. 18, No. 2, Desember 2004. Hlm 134-151.

PUSAIR (Pusat Penelitian dan Pengembangan Sumberdaya Air). 1998. Katalog Sungai Di Indonesia. Volume I. Citarum, Bengawan Solo, Brantas. Bandung.

Raini M., M.J. Herman dan N. Utama. 1995. Kualitas Fisik dan Kimia Air PAM DKI Jakarta tahun 1991 - 2001. Cermin Dunia Kedokteran, Vol. 100, April 1995:50-52.

Yoga, G.P., Y. Sudarso, T. Suryono dan R.L. Toruan. 2006. Toksisitas Air Pori - Pori Sedimen Waduk Saguling, Jawa Barat. Prosiding Seminar Nasional Limnologi 2006, Kamis, 21 Desember 2006, Hal. 352 - 360.

http://www.lipi.go.id/www.cgi?publikasi\&1166670922\&2\&\& (15/3/2007, jam 10.25). 